\title{
AUXILIARY PROPULSION THRUSTER PERFORMANCE WITH ION MACHINED ACCELERATOR GRIDS
}

Wayne R. Hudson

Lewis Research Center

Cleveland, Ohio 44135

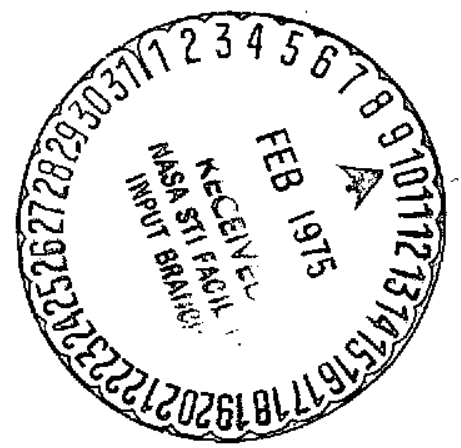

TECHNICAL PAPER to be presented at Eleventh Electric Propulsion Conference sponsored by American Institute of Aeronautics and Astronautics New Orleans, Louisiana, March 19-21, 1975 
AUXILIARY PROPULSION THRUSTER PERFORMANCE WITH ION MACHINED ACCELERATOR GRIDS

Wayne R. Hudson

National Aeronautics and Space Administration

LewIs Research Center

Cleveland, Ohio

\section{Abstract}

A substantial improvement in the performance of an 8-centimeter-diameter auxiliary propulsion thruster has been achleved by reducing the diameter of the accelerator grid aperatures. The accelerator grid hole geometry has been defined by fon machining accelerator grids on an 8-centimeter thruster at thrust levels of $2.2,4.4$, and 6.7 millinewtons (mN). A thruater with an Ion machined accelerator grid has been operated at a thrust of $4.4 \mathrm{mN}$ for 1000 hours. The discharge propellant utilization was $92 \%$ at an eV/ton of 338 . Thruster performance and accelerator grid hole geometry has been documented as a function of thrust level. It was also determined that the small hole acce1erator grid has a very low backstreaming voltage limit. In fact the thruster can be operated with the accelerator grid held at neutralizer tip potential.

\section{Introduction}

A substantial improvement in thruster performance has been achleved by reducing the diameter of the accelerator grid holes. The smaller accelerator grid holes reduce the number of neutral mercury atoms escaping from the discharge chamber thereby increasing the propellant utilization efficiency. Improvements of up to $20 \%$ were obtained at comparable discharge chamber power losses.

The accelerator grid hole geometries were determined by fon machining a blank accelerator grid with an 8-centimeter-diameter-mercury. (1) The screen grid focuses individual ion beamlets onto the blank accelerator grid, selectively sputtering a matching array of holes in the accelerator grid. The resulting accelerator grid holes are individually sized, shaped and allgned with their corresponding screen holes. Each hole is uniquely matched to the beamlet that machined it.

As of December, 1974 four accelerator grids have been ion machined. The first grid (grid 1) was ion machined at $4.4 \mathrm{mN}$ of thrust for over 1000 hours. The second and third grids were machined at accelerated rates and are presently being used in short term thruster tests. The fourth grid (gr1d 4) was used to study the variation of accelerator hole size, shape and geometry with thrust level. The ton machining procedure is included and discussed in the paper.

At each thrust leve1 $(2.2,4.4$, and $6.7 \mathrm{mN})$ the accelerator grid hole geometry and the thruster performance information is presented.

\section{Apparatus and Thruster Configuration}

A 4.5-meter long by 1.5-meter in diameter vacuul facility was employed for both the lon machinIng process and the subsequent thruster operation. The thruster test chamber was connected to the fa- cllity through a $0.3-$ meter gate valve. The facility was malntalned at $10^{-6}$ torr during thruster operation.

The 8-centimeter-diameter thruster used is shown in cross section in Fig. 1 . The thruster had a cylindrical shell engine body 9.3 centimeters in diameter and concentric anode 8.4 centimeters in diameter. Permanent magnets were distributed evenly around the englne body clrcumference, a screen pole plece was in the proximity of the beam extraction system, and a cathode pole plece surrounded the cathode. When the thruster was operated at thrust levels of $2.2 \mathrm{mN}$ and $4.4 \mathrm{mN}$, s1x 0.635 -cent1meterdiameter magnets were used. At the $6.7 \mathrm{mN}$ thrust levels eight magnets were used. The screen pole piece consisted of a cylindrical collar 1.12-cent1meters long and a truncated con1cal surface $0.71-$ centimeters long which formed a $20^{\circ}$ angle with respect to the thruster axis. The cathode pole piece was a contcal design 1.65 centimeters in height and 1.58 centimeters in inside diameter. A $0.508-$ centimeter-diameter tantalum baffle was used at a11 thrust levels. The baffles were all 0.053-centimeters thick. They were mounted in the plane of the downstream edge of the cathode pole plece by three support wires. The main cathode and the neutralizer were both enclosed-keeper hollow cathodes, described in detall in Ref. 1 . The cathode and neutrallzer had 0.25 -millimeter orffices in the cathode tip. The cathode had a 2.5-mi111meter-dlameter keeper orifice. The neutralizer keeper orifice was 1.14 milimeters. Mercury flow measurements were determined by measuring the time rate of change of mercury level in a precision 0.5-millimeter-diameter burette. All the screen and accelerator grids were both hydroformed to a depth of 0.25 centimeter, which corresponds to a radius of curvature of 30 centimeters. The screen grids were 0.40 millimeters thick and had an open area of $72.5 \%(1.97$-man diameter holes on 2.21-m centers). The accelerator grids were unperforated molybdenum sheet 0.38 millimeters thick. The screen and blank accelerator grids were spotwelded to rings and set at a uniform intergrid gap of 0.76 mfllimeter. The gap between grids was intentionally made larger than usual (0.5 $\mathrm{mm})$ to minimize intergrid shorting during the machining process.

The electrical circuit shown in F1g, 2 was used to operate the thruster during ion machining and normal thruster operation. The anode was held at the net accelerating voltage $\mathrm{V}_{\mathrm{I}}$. The cathode was negatively biased by the discharge chamber supply, and the neutralizer floating potential was measured between the neutralizer tip and the facility ground. There were two modifications made in the normal thruster electrical circuit to Implement Ion machinIng: a 4-microfarad capacitor was connected between the accelerator grid and the cathode common, and an accelerator supply was used that had a current capability of 100 milliamperes. The purpose of the capacitor was to prevent flakes of sputtered material from permanently shorting the grids together. When a flake shorted the grids, the capacitor discharged through the flake therby vaporizing 1 t. 
The extra current capacity of the accelerator supply was necessary because in the initial stages of the machining operation the accelerator supply must cary the full lon beam current.

\section{Ion Machining Procedure}

Because the unperforated accelerator grid drastically reduced the normal ion and neutral $106 s$ from the discharge chamber, it was necessary to decrease the mercury flow to a few equivalent milliamperes. The mercury flow rate was regulated to maintain a discharge voltage as close as posib1e to 40 volts consistant with maintaining adequate mercury flow to sustain cathode operation. At the start of the fon machining process, the discharge voltage was near 30 volts. Later, as the ion beamlets aputtered through the accelerator grid, the mercury flow was gradually increased to the normal levels giving a discharge voltage of 35 - 40 volts.

Because the thruster beam current $J_{B}$ was meassured as the current drawn by the neutrallzer (f1g. 2), 1t read zero ag long as there were no holes sputtered through the accelerator grid. The total ion current appeared as accelerator current $\mathrm{J}_{\mathrm{A}}$ and as net-accelerating-potential supply current $\mathrm{J}_{\mathrm{B}}^{\prime}$, since $\mathrm{J}_{\mathrm{B}}^{\prime}=\mathrm{J}_{\mathrm{B}}+\mathrm{J}_{\mathrm{A}}$. These three cur-rents served as conventent parameters for monftoring the machining process. In1tially, $J_{B}$ equaled zero and $J_{B}^{\prime}$ equaled $J_{A}$, but as the holes began to machine through the accelerator grid $J_{B}$ started increasing and $J_{A}$ started decreasing. The relative magnitudes of $J_{B}$ and $J_{A}$ are gens1the 1ndicators of the progress of the ion machining. Starting with a blank accelerator grid, $J_{B}$ increased from zero to the full beam current ( $72 m A$ ) and $J_{A}$ decreased from the full beam current to its equilibrium level.

After 2 hours of ion beam operation, holes began to sputter through the 0.38-milimeter-thick accelerator grid. As might be expected, the first breakthrough occurred in the center of the accelerator grid. The time of breakthrough was denoted by an increase in $J_{B}$ and a decrease in $J_{A}$. Figure 3 is a plot of both normalized accelerator current $\mathrm{J}_{\mathrm{A}} / \mathrm{J}_{\mathrm{B}}^{\prime}$ and normalized beam current $\mathrm{J}_{\mathrm{B}} / \mathrm{J}_{\mathrm{B}}^{\prime}$, that was observed during machining of grid 1 . The accelerator hole breakthrough point is marked as $A^{\prime}$. During the 2-hour period from $A A^{\prime}$ to $B B^{\prime}$, the net-accelerating-potential supply current, $J_{B}^{\prime}$, was held at 72 milliamperes, and the discharge voltage, $\Delta V_{I}$, was, mafntained between 30 and 40 volts by gradually increasing the mercury flow rate. The net accelerating voltage, $V_{I}$, was held at 1220 volts, and the accelerator voltage, $v_{A}$, was matntatned at -300 volts. At point $\mathrm{BB}^{\prime}$ several changes were made in an effort to increase the ion machining rate. $V_{A}$ was changed to -500 volts in an attempt to increase the beamlet diameters. The mercury flow rate was also increased consistent with maximizing $J_{B}^{\prime}$ within the $V_{I}$ supply limit of 100 milliamperes. At a later stage in these experiments the $v_{T}$ supply was modified to be capable of 200 milifamperes. These changes in operating condtions did cause an fncrease in $\mathrm{J}_{\mathrm{A}} /$ $\mathrm{J}_{B}^{\prime}$ that can be noted at point $\mathrm{BB}^{\prime}$ in F1g. 3 . At point $C^{\prime}$ after less than 14 hours, both $J_{A}$ and $J_{1}$ were becoming relatively constant.

Thruster beam current $J_{B}$ was essentially equal to $\mathrm{J}_{\mathrm{B}}^{\prime}$. Accelerator current $\mathrm{J}_{\mathrm{A}}$ was reduced to
$3 \%$ of 1ts original value, but it was otill approximately 10 times the normal $J_{A}$ leve1s, $(0.2-$ $0.3 \mathrm{ma}$ ).

From this point, the accelerator current continued to decrease, but very slowly. Figure 4 gives the variation of $J_{A}$ over 1000 hours of operation. After 1000 hours, $J_{A}$ reached 0.25 milliampere, which was within the range of normal $J_{A}$ levels but still above the lowest values observed, 0.2 mflliampere. The gradual decrease is partially a result of the continued machining by the outer circumference of the beamlets. Because the fringes of the beamlets are less dense than the center, 1t machines at a much slower rate. Another contributlon was made by the defocused beamlets from partially blocked holes at the outer edge of the screen grıd.

The ion machining rate can be accelerated by operating at higher than normal ion beam current. Grids 2 and 3 were both Ion machined at accelerated rates. Grid geometries similar to grid 1 (1000 hr test) were achieved in 150 hours or less. The accelerator grid hole diameters and the variation in the diameters over the face of the grid are dependent on the thruster operating conditions during the lon machining process.

The general technique that produces the best thruster operating conditions $i_{a}$ to machine at the maximum rate in the inftial stages, but to finish the grid by machining at the intended operating conditions. This may subsequently result in a low level of lon machining at normal operating cond1tions. It is probably advisable to fon machine the accelerator grid at thrust levels slightly greater than the intended running level. This would result In a silight performance loss, but it would allow some margin for variations in the thruster operating parameters.

During the early stages of the Ion machining process, frequent grid short circuits were observed (estlmated at one every $5 \mathrm{sec}$ ). The short circuits were caused by flakes of sputtered (accelerator grid) material and were all eliminated by the capacitor discharge. In order to maintain continulty of thruster operation, the cathode and neutralizer were operated at high levels of tip heat (>30 W). This ensured that cathodes could be reignited automatically after outages due to electrical trangients resulting from grid short circuits. Both the cathode and neutralizer inserts suffered from performance deterioration resulting from this abnormal mode of operation.

\section{Results and Discussion}

As of December 1974, four accelerator grids have been Ion machined. Grid 1 was machined at 1 millipound of thrust for over 1000 hours. The second and third grids were machined at accelerated rates and are being used in thruster tests. Grid 4 was uned to study the variation of accelerator hole size and geotmetry as the thrust level was increased.

\section{The Geometry of Ion Machined Accelerator GIIds}

The upstream and downstream faces of the grid assembly (grid 1) after 1006 hours of operation are shown in Fig. 5. Measurements of the accelerator grid hole diameter were made from photomicrographs 
of geveral positions on both sides of the grid.

Because of higher ton beam density in the center of the $\mathrm{grld}$, Ion machining occurred at a faster rate there. After 4 hours, accelerator holes were sputtered through in the center, but not at the outer edges of the grid. Figure 6 is a photomicrograph of a downstream view of the accelerator grid after 4 hours of lon machining. A variation in hole diameter can be noted. A few of the holes were just barely ion machined through, and part of the accelerator grid is shown where holes were not yet sputtered through. Photomlcrographs of part1ally sput tered-through accelerator holes as viewed from the downstream side are shown in Fig. 7. Upstream views of the partially lon-machined reglon of the accelerator grid presented in Fig. 8. Figure 8 (a) is a low-magnification view of a region where some of the holes were Ion machined all the way through and others were only partially through the 0.38 millimeter-thick accelerator. The acce1erator and screen grid remained mounted on the grid assembly during photographing, and as a consequence the upstream photographs include the screen grid. F1gure $B(b)$ is a high-magnification view of one particular accelerator hole, showing the upstream and downstream perimeters of the hole. The individual beamlets appear to be focusing at a point downstream of the accelerator grid.

Table I shows the time variation of the hole diameters at four different positions on the accelerator grid. At some locations the machining process achleved the equilibrium hole diameter and at some it did not.

Near the outer edges of the accelerator grid the Ion machining process was slower and more complex in structure. Measurements Indicated that on the downstream side the edge holes Increased in size throughout the test but that on the upstream side they stabilized after 462 hours. On the upstream side of the accelerator grid the holes were circular, but on the downstream side of the accelerator grid the holes more closely approximated hexagons. Figure 9(a) is a photomf crograph of several holes after 462 hours of ion machining. The hexagonal pattern appears to be a result of the screen hole array pattern. The sides of a particular hexagon are roughly perpendicular to lines connecting the center of the hexagon to its nearest neighbors. Figure $9(\mathrm{~b})$ is a higher magnification photomicrograph of an accelerator hole.

At the end of the 1000-houx test it was noted tha that on the downstream side of the accelerator grid, the holea midway between the center of the grid and the edge were smaller than the holes at the edge. Measurements showed that the hole diameter at the midway point was $0.74 \mathrm{millime}$ ter on the downstream side, which is smaller than the distance between opposite vertices of the hexagons at the grid edge. Measurements were also made of the hole dlameter midway between the center and edge on the upstream surface of the accelerator grid. In this case the diameter was measured to be 0.94 millimeter, which is intermediate to center-hole diameter and edge-hole diameter.

Charge exchange eroston was observed on the downstream side of the accelerator grid. (10) The darker-colored hexagon web structure is the region that has been aputtered by charge exchange tons. The charge exchange pattern was most intense in the center of the grid.
The accelexator grid and screen grids were spotwelded to a pair of mounting rings. The accelerator grid mounting ring was sputtered by ion beamlets from partially covered screen holes. Figure 11 is a photomicrograph of the sputtered grooves in the accelerator grid mounting ring, No partially covered screen holes would exist on flight type hardware and thus the sputtering of mounting rings would not occur.

In some cases, accelerator grid material sputtered onto the inside of the screen holes. Photomicrographs of two specific examples are shown in Fig. 12. These photographs were taken after 20 hours. As would be expected, the fastest rate of deposit occurred during the first few hours. In some cases the deposited material spalled, partially blocking the screen hole and defocusing the 1on beamlet. Two examples of distorted accelerator grid holes are shown in Fig. 13. There were only seven distorted holes. This effect could be ellminated by more frequent cleaning during the early stages of fon machining. The grid syatem was cleaned of sputtered material five times over the 1000 hours of this test. Although no permanent short circuits resulted, more inspections and cleanings, especially early in the machining process, are recommended. The screen grid deposits were sandblasted away after 149 hours. Subsequent inspections did not reveal additional deposits.

Tab1e II shows the results of an experiment, where the fon beam machining level was varied and the resulting accelerator grid (grid 4) was documented. The machining was done on one accelerator grid, operating sequentially at beam currents of 36,72 , and 108 millianperes. These beam currents correspond to thrust levels of $2.2,4.4$, and 6.7 $\mathrm{mN}$ respectively. About 100 hours of machining was involved at each beam level. Accelerator grid hole dimensions are tabulated for center holes and edge holes on the upstream and downstream faces. Data from the 1000 hour grid is included for comparison.

A few Interesting trends occur in the data. The edge holes increased in diameter only very slightly when the ion beam current was 1ncreased. At 36 milliampere beam current, the edge holes on the upstream side of the grid were only silghtly smaller than the center holes. On the downstream side, the edge holes were actually larger than the center holes. At 108 milliampere the upstream edge hole diameter had only increased to 0.84 millimeter.

In contrast, center hole diameter increased more sharply with increasing beam current. On the downstrean side the Increase was proportional to the beam current. On the upstream side neither the hole diameters nor hole area were proportlonal to beam current.

\section{Thruster Performance}

The accelerator holes resulting from the ion machining process are optimally sized the to the ton beamlets. The smaller accelerator holes result in reduced neutral mercury loss, which in turn enhances the propellant utilization.

The discharge propellant utilization $n_{\text {in }}$ is equal to the ratio of beam current to total mercury flow 


$$
\eta_{u}=\frac{J_{B}}{J_{B}+J_{N}}
$$

where $J_{f} 1$ s equal to the un-1onized part of the total metcury flow. If it is assumed that the neutral loss rate from the discharge chamber is proportional to the open area of the accelerator grid and is distributed uniformly over the area. Then

$$
\frac{\mathrm{J}_{\mathrm{NI}}}{\mathrm{J}_{\mathrm{N} 2}}=\frac{\mathrm{A}_{1}}{\mathrm{~A}_{2}}=\frac{\mathrm{D}_{1}^{2}}{\mathrm{D}_{2}^{2}}
$$

where $A_{1}$ and $A_{2}$ are two different open areas and $D_{1}$ and $D_{2}$ are the corresponding accelerator hole diameters. Then glven empirical results of a particular accelerator hole dianeter a relation can be derived for the approximate propellant utilization as a function of accelerator hole diameter. For $\mathrm{D}_{1}=1.69 \mathrm{~m}-11$ lmeters and $\mathrm{J}_{\mathrm{B}}=72$ mill lamperes, thrusters have operated at $70 \%$ propellant utilization, at discharge losses of 300 to $350 \mathrm{ev} /$ ion. From Equa. (1) J $\mathrm{J}$ can be calculated to be 30.8 milliamperes. Then using Equas. (1) and (2)

$$
\eta_{\mathrm{u} 2}=\frac{\mathrm{J}_{\mathrm{B}}}{\mathrm{J}_{\mathrm{B}}+\mathrm{J}_{\mathrm{N} 1} \frac{\mathrm{D}_{2}^{2}}{\mathrm{D}_{1}^{2}}}=\frac{1}{1+\frac{\mathrm{J}_{\mathrm{N} 1}}{\mathrm{~J}_{\mathrm{B}}} \frac{\mathrm{D}_{2}^{2}}{\mathrm{D}_{1}^{2}}}
$$

substituting values for $J_{N I}, J_{B}$, and $D_{1}$ ylelds

$$
n_{u}=\frac{1}{1+0.149 D^{2}}
$$

The coeffictents of $\mathrm{D}^{2}$ in Equa. (3) have been calculated for thruster performance at beam currents of 36 milliamperes and 108 milliamperes. The values are 0.29 and 0.087 respectively. The discharge chamber propellant utilizations calculated from Equa. (3) are plotted versus accelerator grid hole diameter for three lon beam current operating levels (fig. 14). Large increases in propellant utilization are predicted for small hole accelerator grids. Practically, the fon beamlet diameter represents a lower Iimit to the accelerator grid hole dfameters. As demonstrated by the results of Ion machining experiments, if the accelerator holes are amaller in diameter than the beamlet diameter they will be enlarged by sputtering. Comparing the utilizations (fig. 14) with respect to beam current at a constant accelerator grid hole diameter indicates how utilization should increase as a function of beam current.

Because the hole diameter of the ion machined accelerator grid varles with respect to hole locat1on, thruster performance with Ion machined grids can not be directly compared with Fig. 14. A conservative but reasonable choice is the accelerator grid hole diameter measured in the center of the grid on the downstream side. If the values listed In table II are used, the profected utilizations are shown in $\mathrm{Fig} .14$ as solid circles. Discharge chamber propellant ut1lization efficienctes of $92 \%$ are predicted in all three cases.

The discharge chamber losses are plotted as a function of the discharge chamber propellant utilization in Flg. 15 for a thruster with an ionmachined accelerator grid, at 149 and 1006 hours, and the same thruster with a Large-Hole Accelerator Grid (LHAG).

The LHAG had a hole diameter of 1.69 millimeters. The Small-Hole Accelerator Grid (SHAG) that resulted from ton machining is clearly superfor. It performs at lower discharge chamber losses and yet much higher propellant efficiencles. During most of the fon machining experiment the SHAG thruster was run at near $90 \%$ utilization and with discharge lasses of $325 \mathrm{eV} /$ ion. A complete set of SHAG thruster operating parameters is shown in table III. For comparison, the sma11-thruster program goals and the operating parameters of the LHAG thruster are listed. The SHAG thruster closely approximates the program goals. The smal1-thruster program goal for total efficlency is $57.5 \%$, and the SHAG thruster operated at $56.7 \%$.

The LHAG configured thruster was teated at two operating points. The first operating point was with the same mercury flow rate and discharge power as the SHAG thruster. The LHAG thruster produced a beam current of 59.8 milliamperes, which corresponds to a thrust of $4.18 \mathrm{mN}$ at 465 eV/lon. The second test was with the mercury flow rate Increased such that the thruster could produce a 72-millianpere beam current (5,16-mN thrust). This point is listed in table III. A mercury flow rate of 106 mill1amperes was required. Propellant utilization was below $70 \%$, at $381 \mathrm{ev} /$ ion. The lower propellant ut1lization decreased the spectfic impulse to 2247 seconds.

In Fig. 15, two curves are graphed for the SHAG thruster, one after 149 hours and one after 1006 hours. Comparison of the SHAG thruster curves revea1s a $3 \%$ decrease in propellant utilization with time. It was probably a result of an increase In the diameter of the accelerator grid holes.

Figure 16 shows the discharge losses as a function of propellant utilization at beam current levels of 36,72 , and 108 milliamperes. Al1 the data taken was at net accelerating voltage of 1220 volts and accelerator voltage of -300 volts. Also listed are ranges of $\Delta V_{I}$ for each curve. The open symbols are for the accelerator grid geometries 1isted in table II. At beam currents of 36 milliamperes and 72 milliamperes F fg. 16 shows that the highest propellant utilization was very nearly the value predicted in F1g. 14. Without making any changes in the thruster conflguration it was possible to run efficiently at either 36 milliamperes or 72 milliamperes beam current by only changing the accelerator grid. By increasing the magnetic fleld with the addition of two magnets the thruster could be operated at 108 milliamperes beam current. The maximum utilization achleved decreased to $84.5 \%$, which was below the predicted level of Fig. 14. In fact, the maximum beam current was only slightly greater than 108 milliampere even though the discharge chamber losses were higher. The difference between the predicted performance and that achleved was due to the low discharge voltage of 35.5 volts. Improved performance could probably have been achleved by increasing the baffle diameter. Table IV lists the measured thruster operating parameters at the 
three beam current levels. The thruster data show for 72 milliamperes was from grid 1, the data for 35 milltampere and 108 milliampere was obtained on grid 4.

Thruster data was also recorded at lower beam current levels after the accelerator grid holes were enlarged by machining at higher beam levels. For example, thruster data was taken at 36 milliamperes after fon machining had been completed at 72 milliamperes and at 108 milliamperes. The highest efficiency operating points are plotted in Fig. 16. The maximum propellant utilization drops off sharply as the accelerator grid holes increase in diameter. After mechining at $72 \mathrm{~m} 111$ iamperes the maximum propellant utilization was $86 \%$ at $290 \mathrm{eV} /$

ion. When the accelerator grid holes were enlarged further by machining at 108 milliamperes, the max-

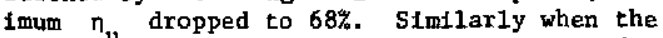
thruster was operated at 72 milliamperes after machining at 108 milliamperes the maximum $\eta_{\text {de- }}$ creased to $82 \%$. The accelerator hole daameters corresponding to machining at these beam levies are tabulated in table II.

The backstreaming limit is defined as the accelerator grid voltage level where electrons can backstream into the dishcarge chamber. It is characterized by an increase in beam current. The backstreaming limit of the small hole accelerator grids were sufficlently low so that the thruster could be operated with the accelerator supply turned off. (The backstreaming limit of the LHAG thruster was about -200 volts.) The net accelerating voltage was increased to maintain the same total voltage. When the accelerator supply was turned off the accelerator grid was at neutralizer tip potential. Figure 17 exhibits the dependence of accelerator current on total voltage with the accelerator voltage at 0 or -300 volts. At the same total voltage the accelerator current with zero accelerator voltage was slightly less than with -300 volts applied to the accleerator grid. Similar results were obtalned for beam currents of 36 milliamperes and 108 milliamperes. The thruster has been run at each thrust level for 24 hours with the accelerator supply turned off. Operating the thruster without an accelerator supply would result in a savings in welght and complexity of the thruster system.

\section{Concluding Remarks}

A substantial 1mprovement in thruster performance has been achleved by reducing the diameters of the accelerator grid holes. At beam currents of 36 milliamperes $(2.2 \mathrm{mN})$ and at 72 milliamperes (4.4 mN) an 8-centimeter thxuster was operated at chamber propellant utilizations of greater than $90 \%$. At a beam current of 108 milliamperes $(6.7 \mathrm{mN})$ the thruster was operated at $84.5 \%$. The accelerator gride were fon machined by operating an 8-centimeter diameter thruster with an inftially unperforated accelerator grid.

A thruster was operated at the 72 miliamperes beam current level $(4.4 \mathrm{mN})$ with an ion machined accelerator grid for over 1000 hours. The electron backstreaming limit was found to be suff 1 clently low so that the thruster could be operated with the accelerator supply shutoff.

\section{Appendix - Symbols}

D

$I_{\text {sp }}$

$\mathrm{J}_{A}$ accelerator drain current, mA

$\mathrm{J}_{\mathrm{B}}$ ion beam current, $A$

${ }^{\mathrm{C}} \mathrm{CH}$ cathode heater current, A

${ }_{\text {CK }}$ cathode keeper current, A

$\mathrm{J}_{\mathrm{E}} \quad$ cathode emission current, A

$\mathrm{J}_{\mathrm{NH}}$ neutralizer heater current, A

$\mathrm{J}_{\mathrm{NK}}$ neutralizer keeper current, A

$v_{\text {A }}$ accelerator voltage, V

$V_{\mathrm{CH}}$ cathode heater voltage, $\mathrm{V}$

$\mathrm{V}_{C K}$ cathode keeper voltage, $\mathrm{V}$

$v_{g}$ neutralizer floating potent1al, $v$

$v_{I}$ net accelerating potential, V

$\Delta V_{I}$ diacharge voltage, $v$

$v_{\mathrm{NH}}$ neutralizer heater voltage, $v$

$\mathrm{V}_{\mathrm{NK}}$ neutralizer keeper voltage, $\mathrm{v}$

$E_{I}$ electron volts per beam ion, eV/ion

$\eta_{u}$ Ion thruster mass utilization efficlency, dimensionless

\section{References}

1. Hudson, W. R. and Banks, B. A., "An 8-cm Electron Bombardment Thruster for Auxlllary Propulsion," AIAA Paper 73-1131, Lake Tahoe, Nev., 1973. 
Table I Accelerator grid hole diameters

\begin{tabular}{|c|c|c|c|c|}
\hline $\begin{array}{c}\text { Operating } \\
\text { time, } \\
\text { hr }\end{array}$ & \multicolumn{2}{|c|}{ Upstream side of grid } & \multicolumn{2}{c|}{ Downstream side of grid } \\
\cline { 2 - 5 } & $\begin{array}{c}\text { Center-hole } \\
\text { diameter, } \\
\text { mmm }\end{array}$ & $\begin{array}{c}\text { Edge-hole } \\
\text { diameter, } \\
\text { mm }\end{array}$ & $\begin{array}{c}\text { Center-hole } \\
\text { diameter, } \\
\text { mm }\end{array}$ & $\begin{array}{c}\text { Edge-hole } \\
\text { diameter, } \\
\text { mm }\end{array}$ \\
\hline 4 & 0.68 & $(a)$ & 0.47 & b (a) \\
20 & .84 & 0.72 & .64 & $0.51-0.61$ \\
149 & -83 & .83 & $0.61-0.69$ \\
462 & 1.04 & .86 & .83 & $0.71-0.76$ \\
1006 & 1.12 & .86 & .83 & 0.82 \\
\hline
\end{tabular}

at sputtered through.

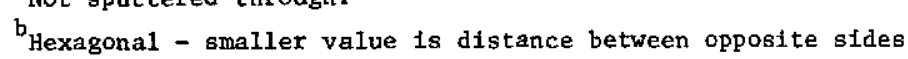
of hexagon; larger value is distance between opposite vertices of hexagon.

Table II Accelerator grid hole diameters resulting from three fon beam machining levels.

\begin{tabular}{|c||c|c|c|c|}
\hline \multicolumn{1}{c|}{} & \multicolumn{2}{c|}{ Upstream } & \multicolumn{2}{c|}{ Downstream } \\
\hline $\begin{array}{c}\mathrm{J}_{\mathrm{B}} \\
\mathrm{ma}\end{array}$ & $\begin{array}{c}\text { Center } \\
\text { mm. }\end{array}$ & $\begin{array}{c}\text { Edge } \\
\text { mm. }\end{array}$ & $\begin{array}{c}\text { Center } \\
\text { mm. }\end{array}$ & $\begin{array}{c}\text { Edge } \\
\text { mm. }\end{array}$ \\
\hline 36 & 0.86 & 0.80 & 0.53 & $0.58-0.64$ \\
72 & $1.12^{*}$ & $0.86^{*}$ & $0.83 *$ & $0.71-0.82$ \\
108 & 0.95 & 0.80 & 0.76 & $0.61-0.67$ \\
1.19 & 0.84 & 0.99 & $0.64-0.71$ \\
\hline
\end{tabular}

${ }^{\dagger}$ Non circular holes

* Iata from 1000 hour grid 
Table III Compartson of 8-cent1meter-diameter ion thruster operating conditions

\begin{tabular}{|c|c|c|c|}
\hline & $\begin{array}{c}\text { Program } \\
\text { goal }\end{array}$ & $\begin{array}{l}\text { Small-hole } \\
\text { accelerator } \\
\text { grid conditions }\end{array}$ & $\begin{array}{l}\text { Large-hole } \\
\text { accelerator } \\
\text { grid conditions }\end{array}$ \\
\hline 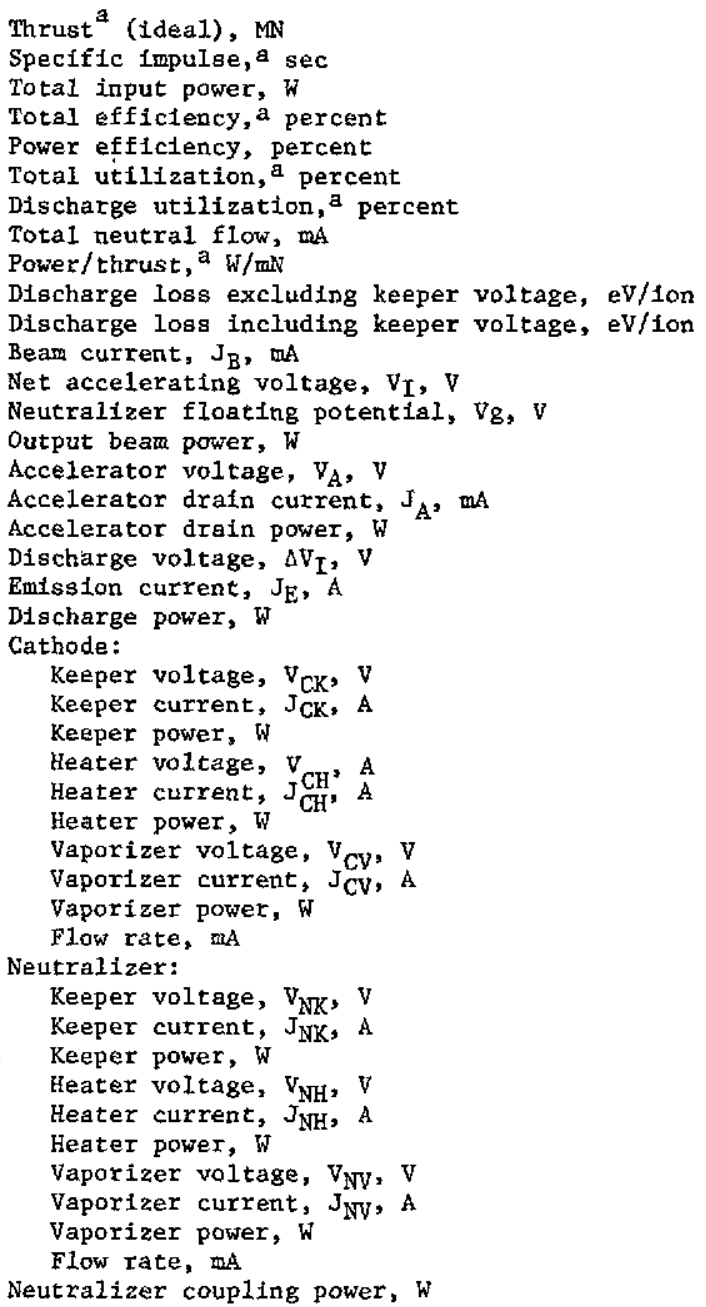 & $\begin{array}{r}5.07 \\
2804 \\
122.19 \\
57.5 \\
71.3 \\
80.6 \\
86.4 \\
89.3 \\
24.15 \\
294 \\
328 \\
72 \\
1220 \\
-10 \\
87.12 \\
-500 \\
0.23 \\
0.40 \\
40 \\
0.53 \\
21.2 \\
\\
10.0 \\
0.240 \\
2.4 \\
0 \\
0 \\
0.72\end{array}$ & $\begin{array}{r}5.16 \\
2958 \\
131.54 \\
56.7 \\
66.4 \\
85.4 \\
91.9 \\
85.2 \\
25.49 \\
286 \\
338 \\
72.8 \\
1220 \\
-20 \\
87.36 \\
-300 \\
0.25 \\
0.38 \\
38.5 \\
0.54 \\
20.79 \\
\\
17.5 \\
0.22 \\
3.85 \\
0 \\
0 \\
0 \\
1.46\end{array}$ & $\begin{array}{r}5.16 \\
2247 \\
134.21 \\
42.2 \\
65.3 \\
64.6 \\
68.3 \\
112.0 \\
26.00 \\
369 \\
381 \\
72.4 \\
1220 \\
-10 \\
87.60 \\
-300 \\
0.35 \\
0.53 \\
40.5 \\
0.66 \\
26.73\end{array}$ \\
\hline
\end{tabular}

*Accounting for neutralizer floating potential but neglecting beam divergence and double ionization. 
Table IV 8-cm ion thruster operating conditions at $35 \mathrm{ma}, 72 \mathrm{ma}$ \& $108 \mathrm{ma}$ beam current

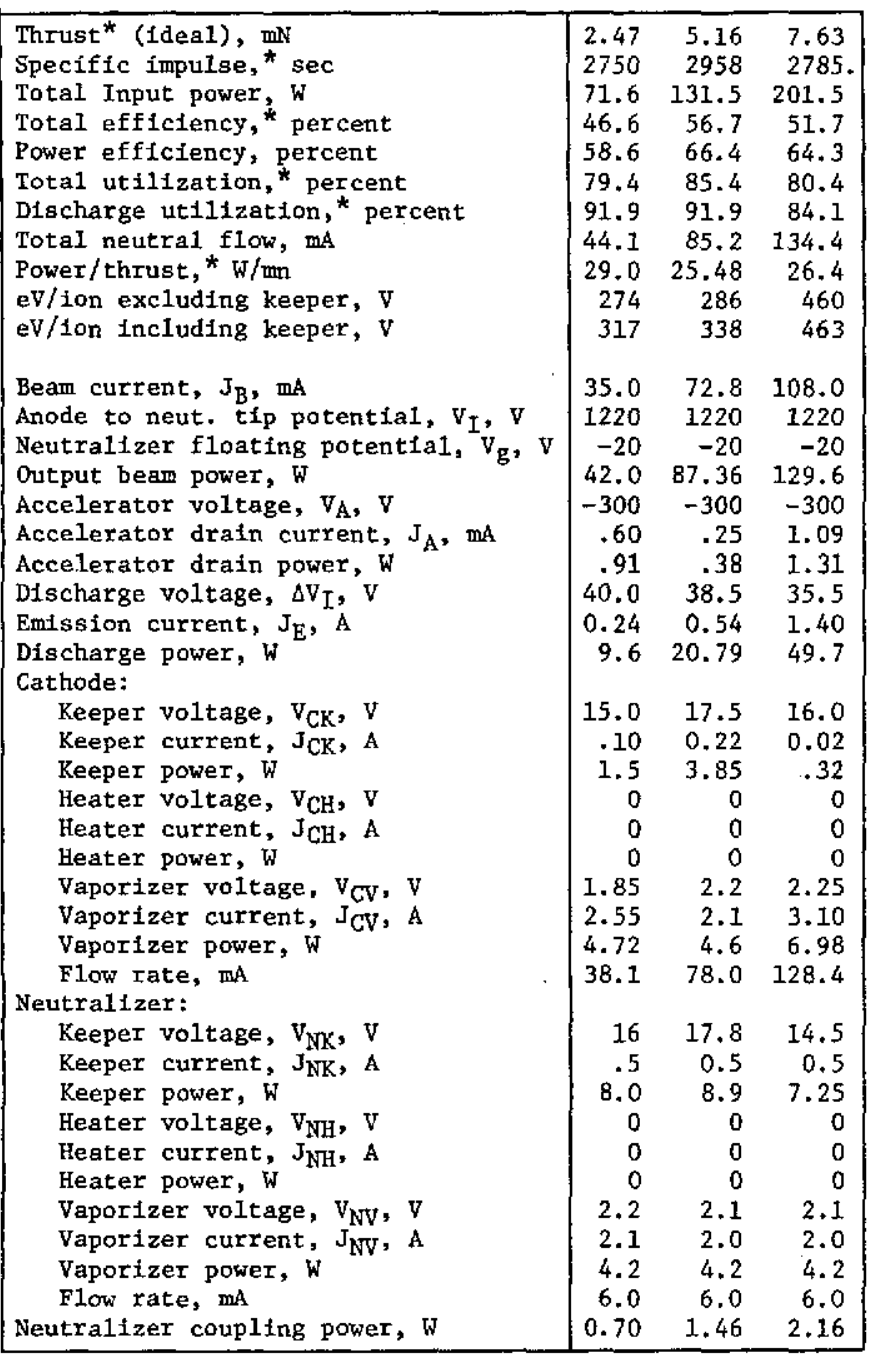

* Accounting for neutralizer floating potential but neglecting beam divergence and double ionization.

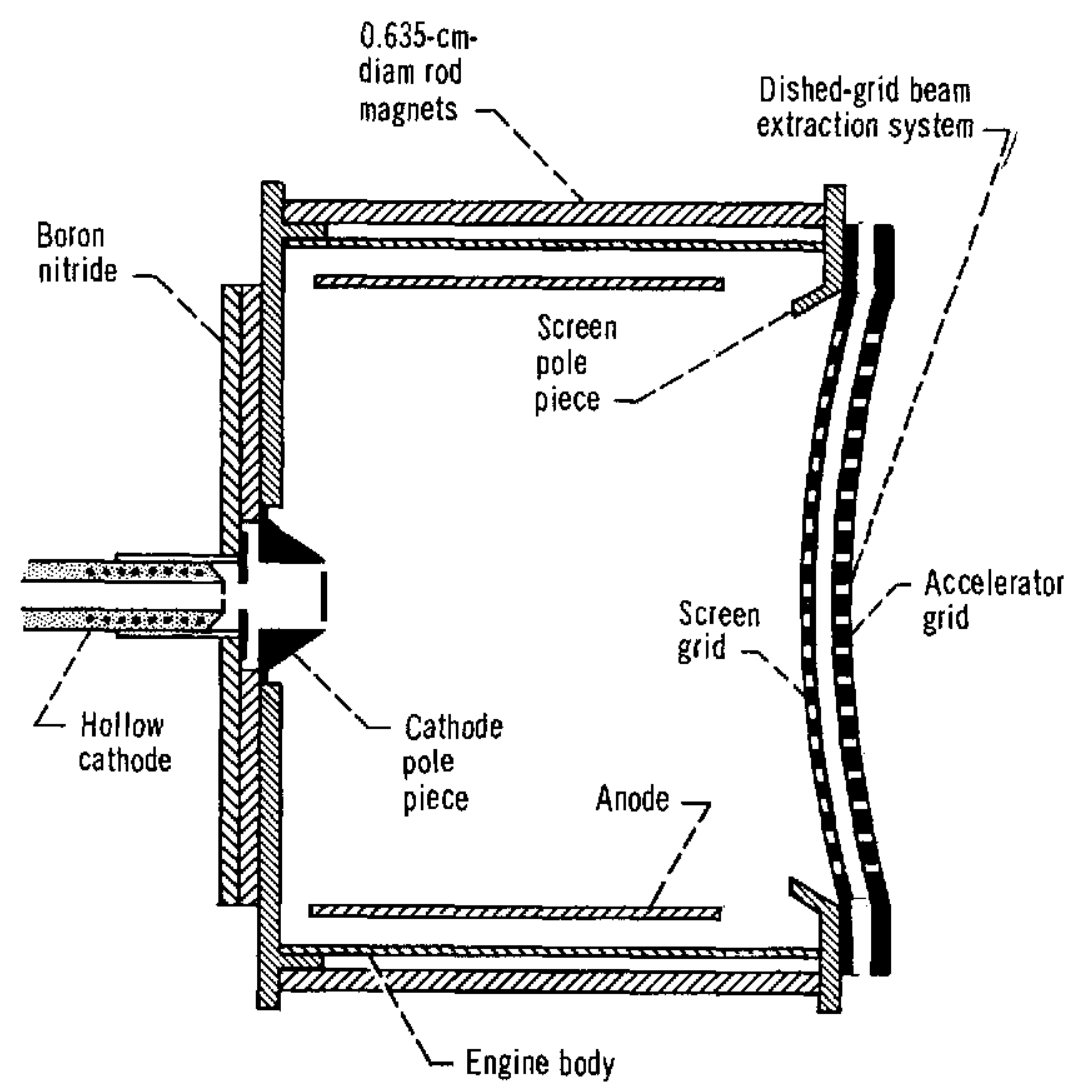

Figure 1. - Cross section of 8-centimeter-diameter thruster discharge chamber with dished-grid beam extraction system. 


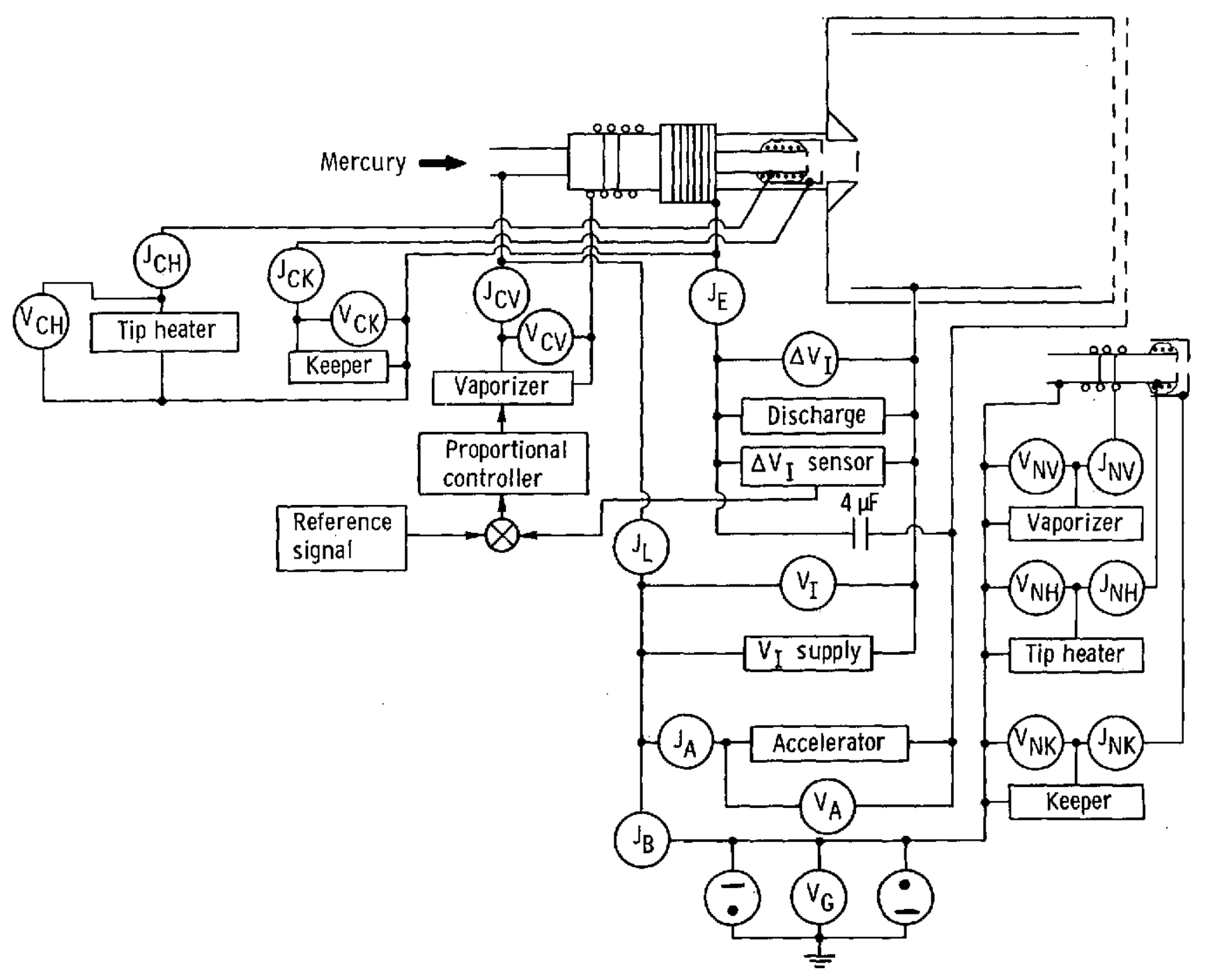

Figure 2. - Electrical circuit used for thruster testing. 


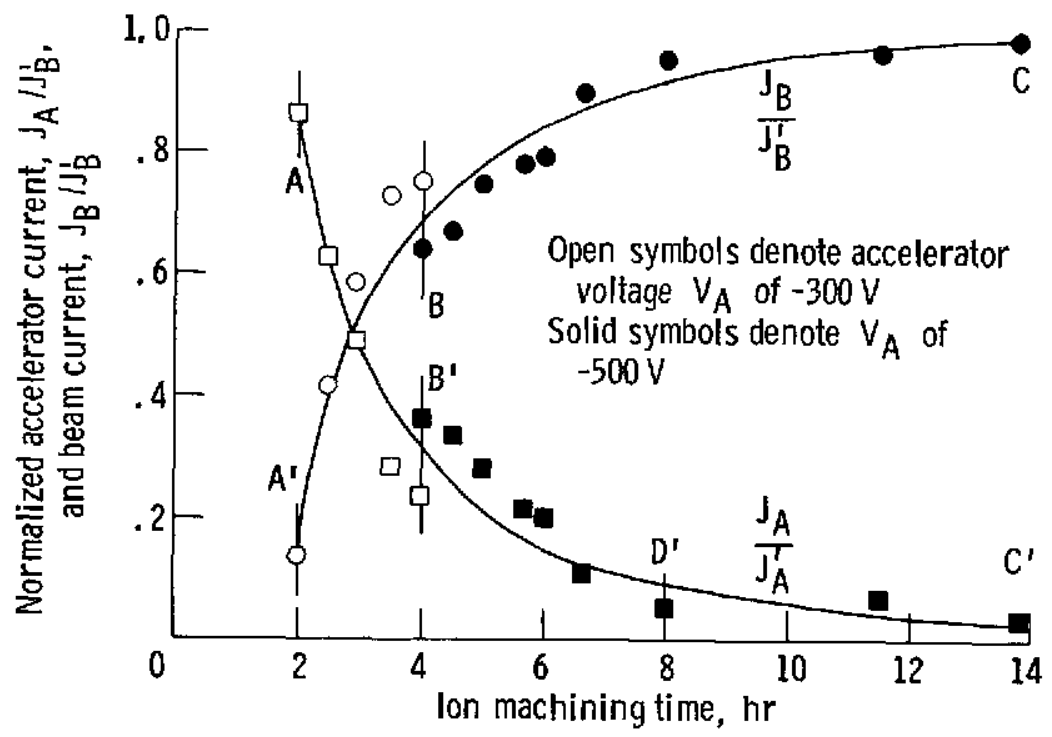

Figure 3. - Normalized accelerator current and normalized beam current as function of ion machining time, where $\mathrm{J}_{\mathrm{B}}$ is current measured on $V_{I}$ supply. Net accelerating voltage, $V_{I}, 1200$ volts.

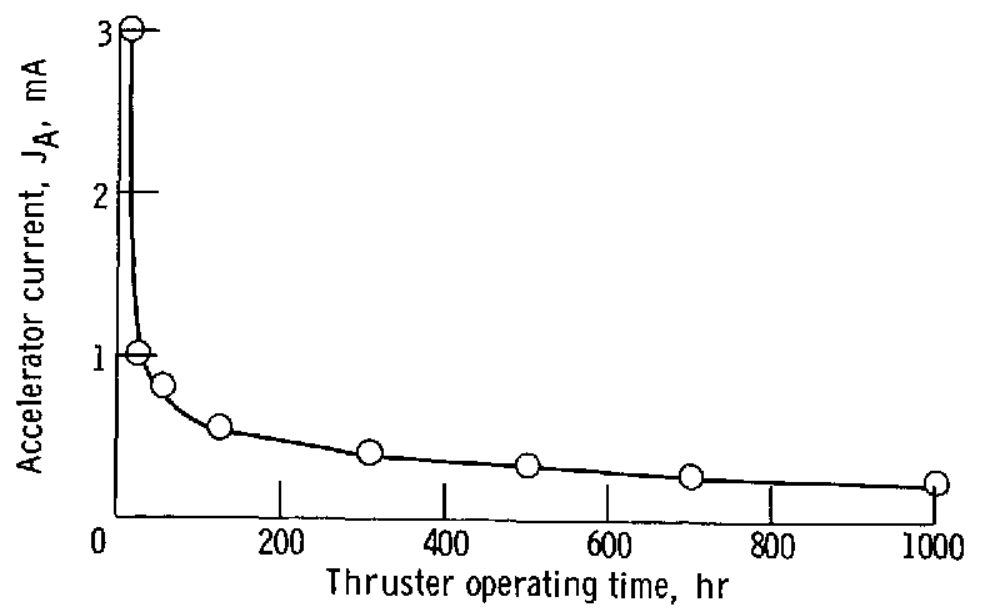

Figure 4. - Variation of accelerator current with thruster operating time. 


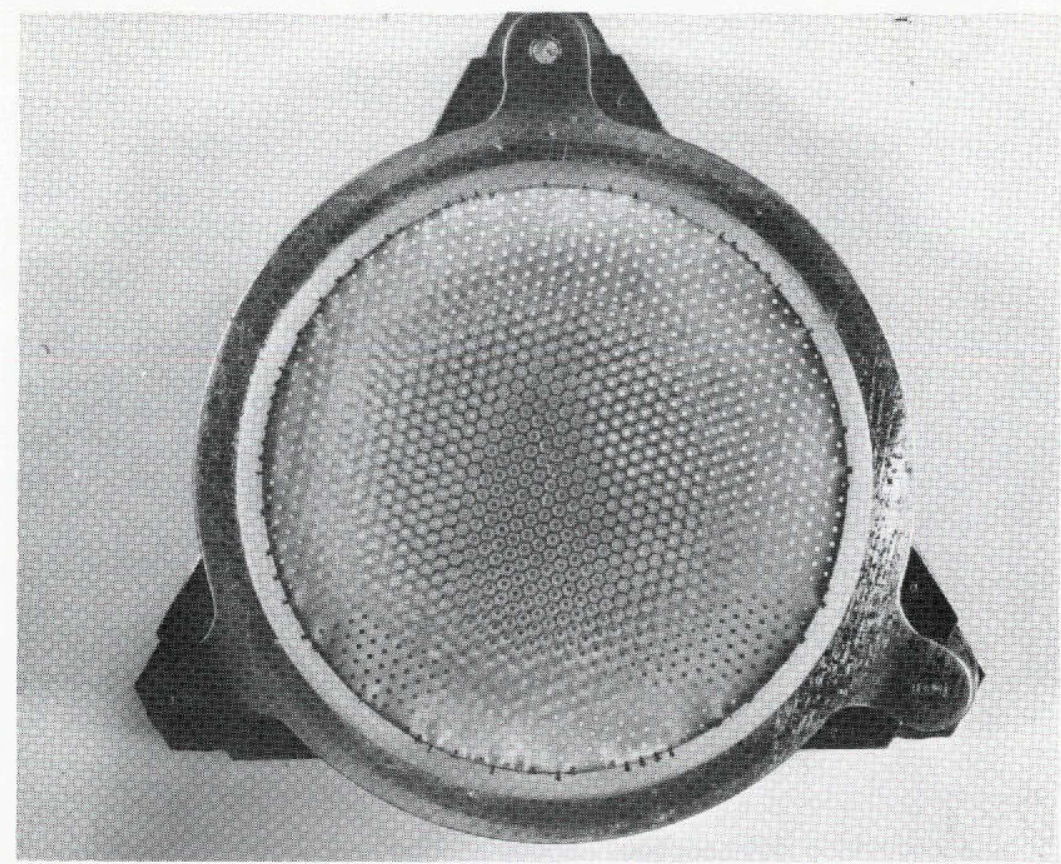

Downstream face

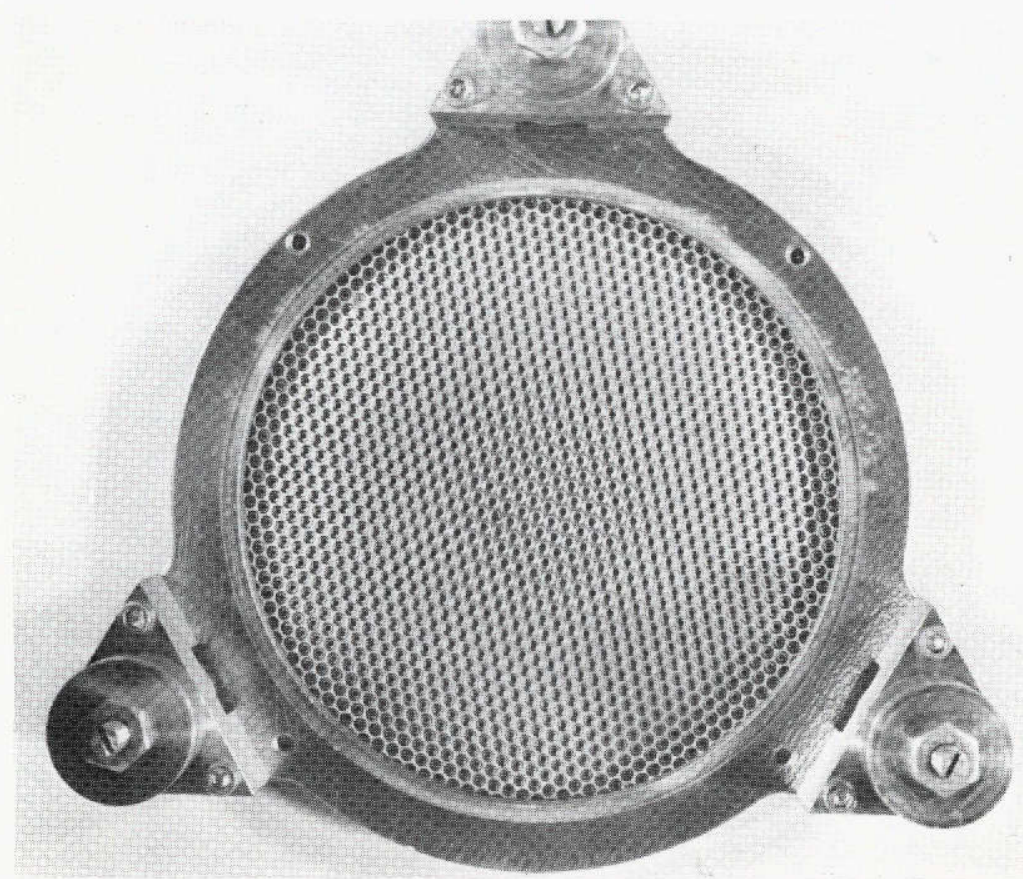

Upstream face

Figure 5. - Upstream and downstream views of thruster grid assembly after 1006 hours of operation. 


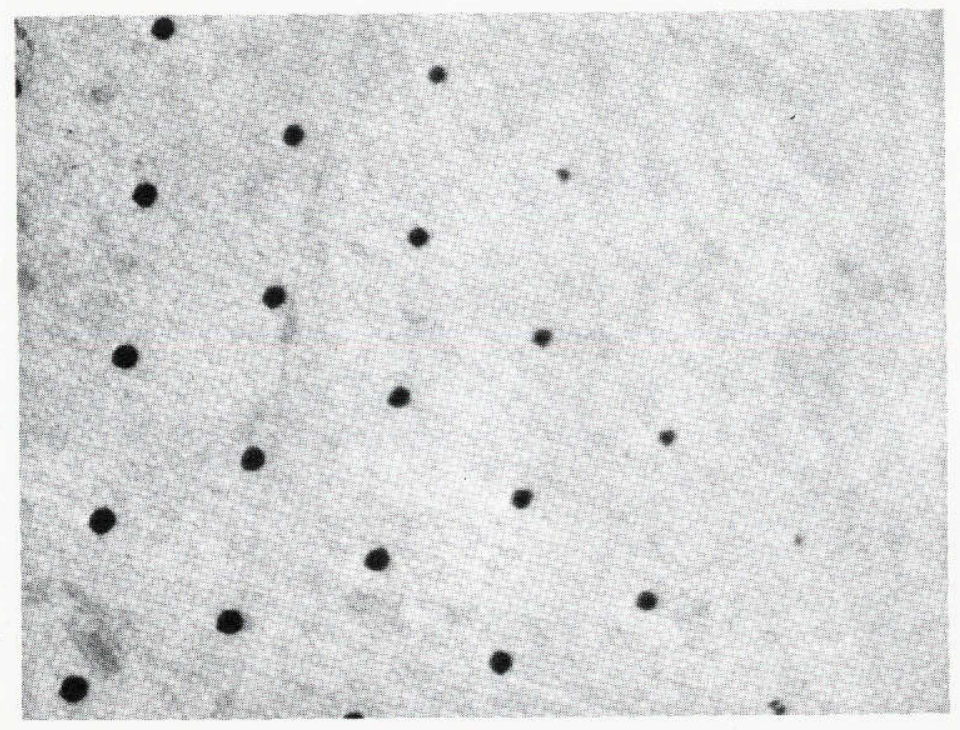

Figure 6. - Photomicrograph of downstream face of accelerator grid after 4 hours of ion machining.

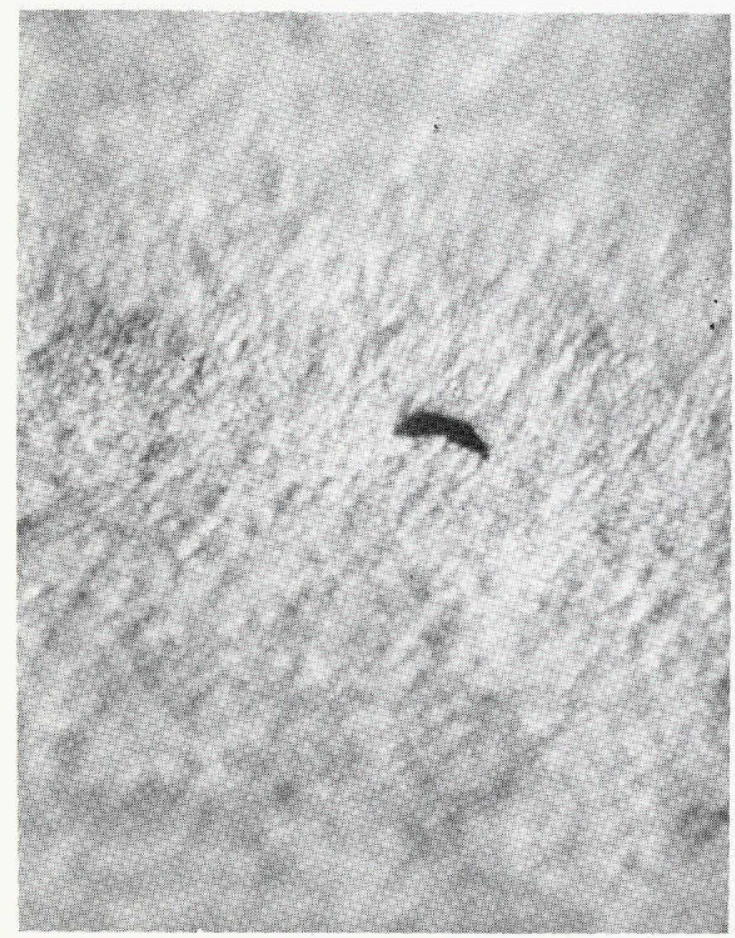

(a)

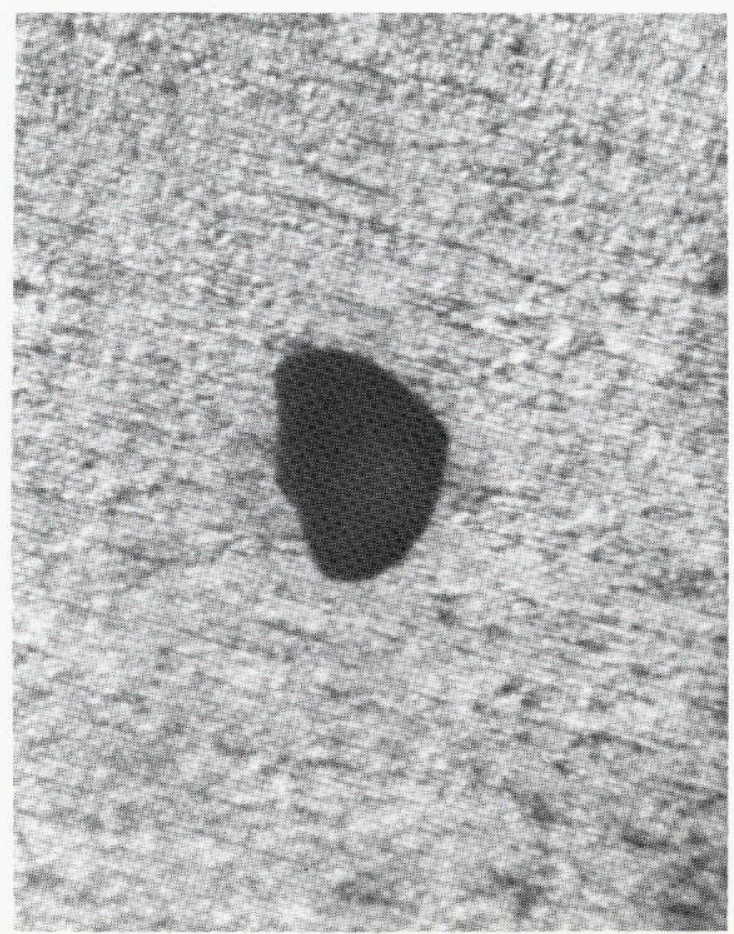

(b)

Figure 7. - Photomicrographs of partially sputtered-through accelerator holes viewed from downstream side of accelerator grid. 


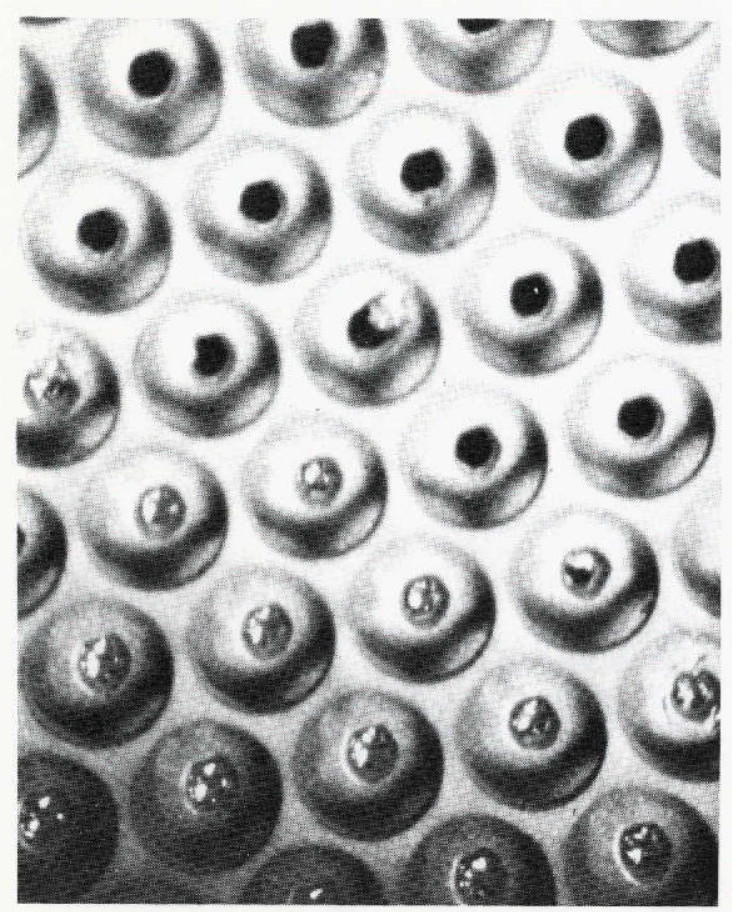

(a)

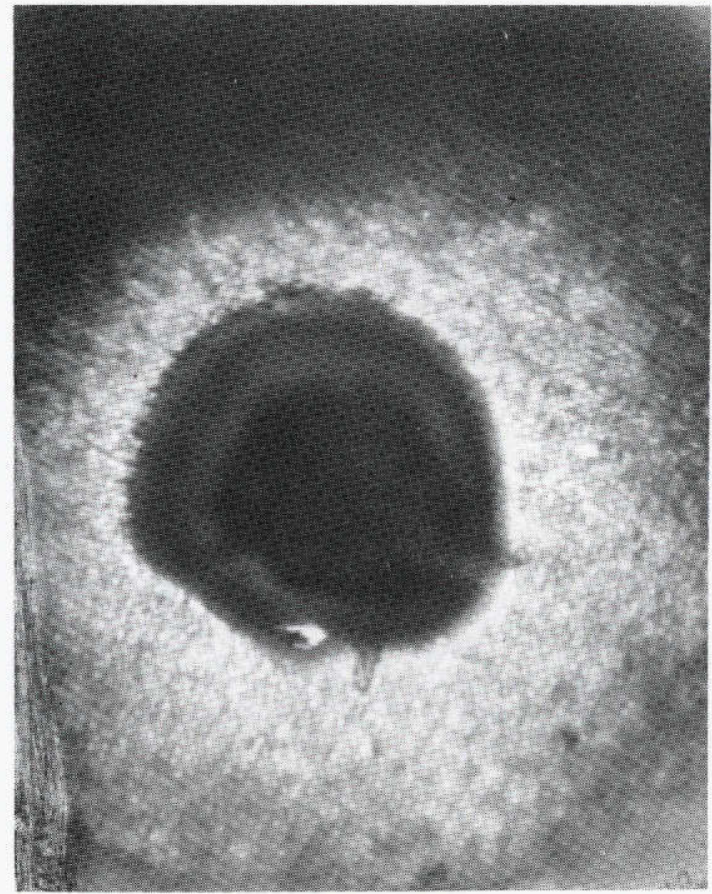

(b)

Figure 8. - Photomicrographs of partially sputtered-through accelerator holes viewed from upstream side of accelerator grid. 


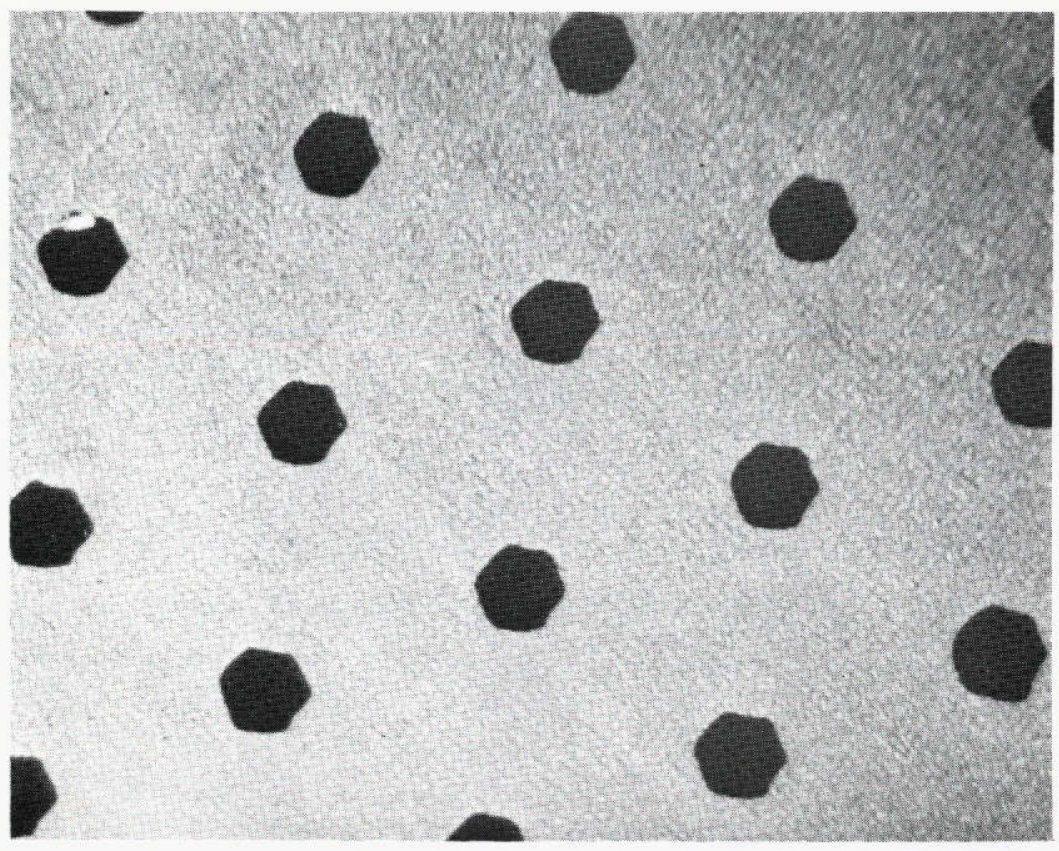

(a)

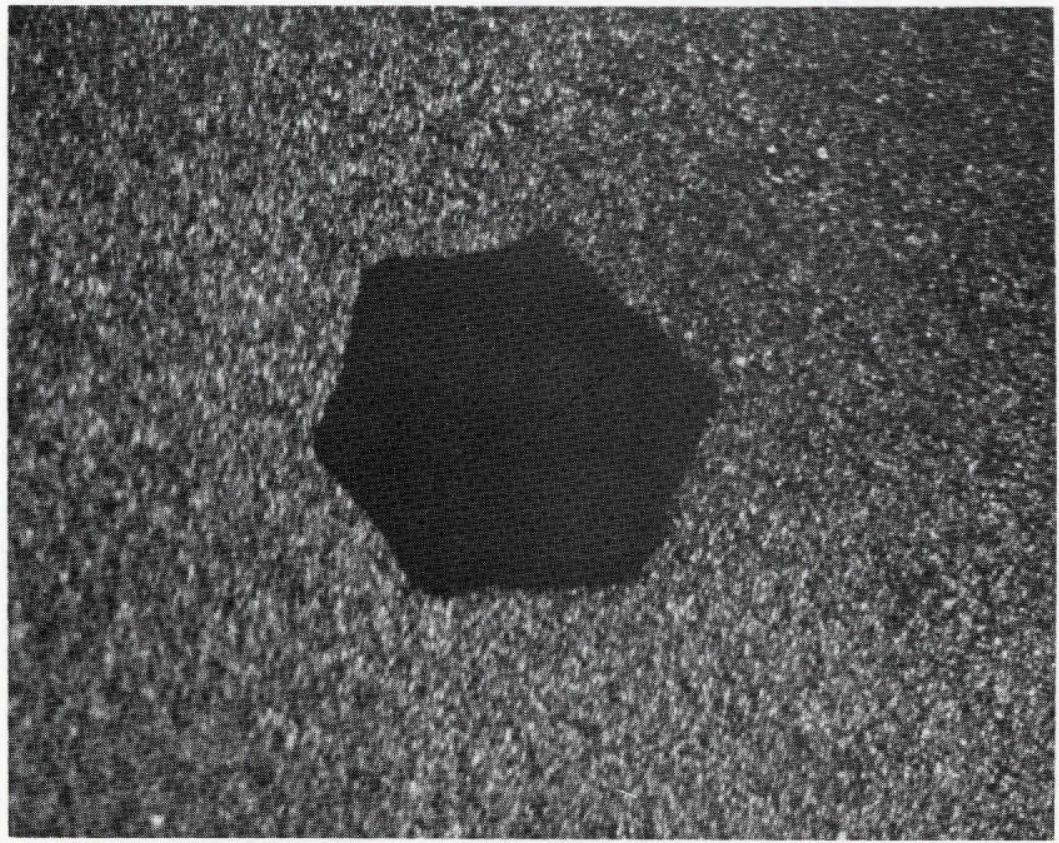

(b)

Figure 9. Photomicrographs of hexagon accelerator hole geometry viewed from downstream side of grid after 462 hours of operation. 


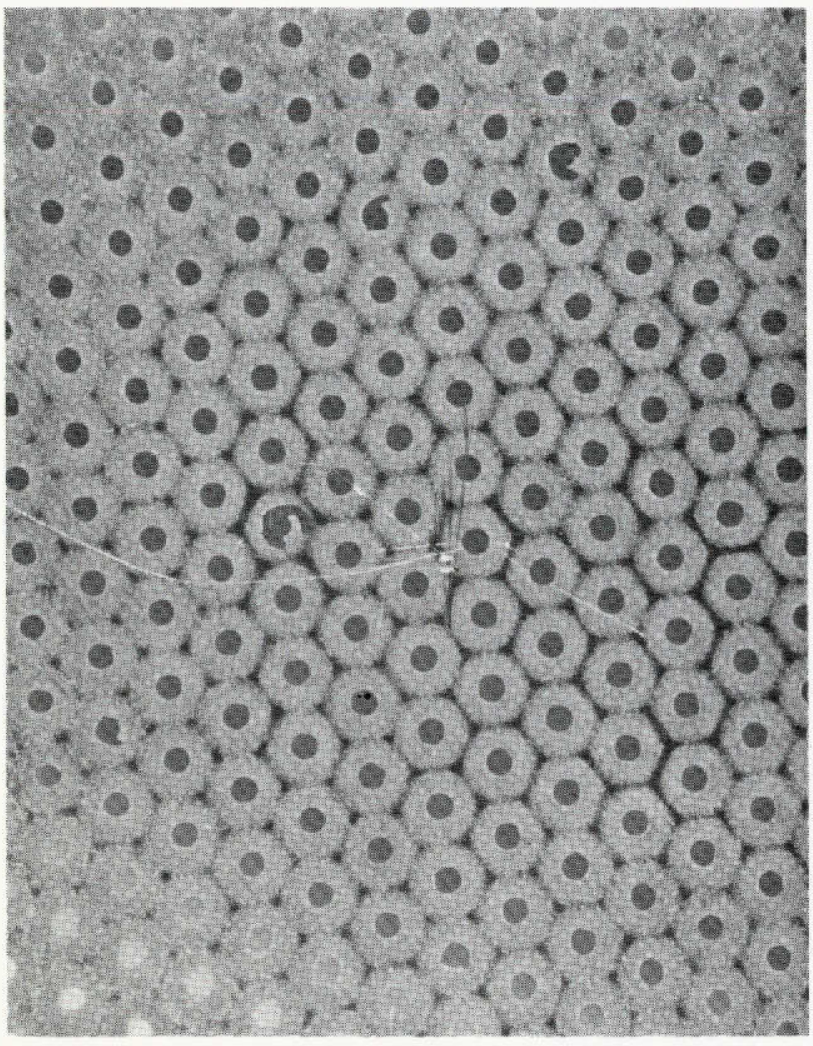

(a)

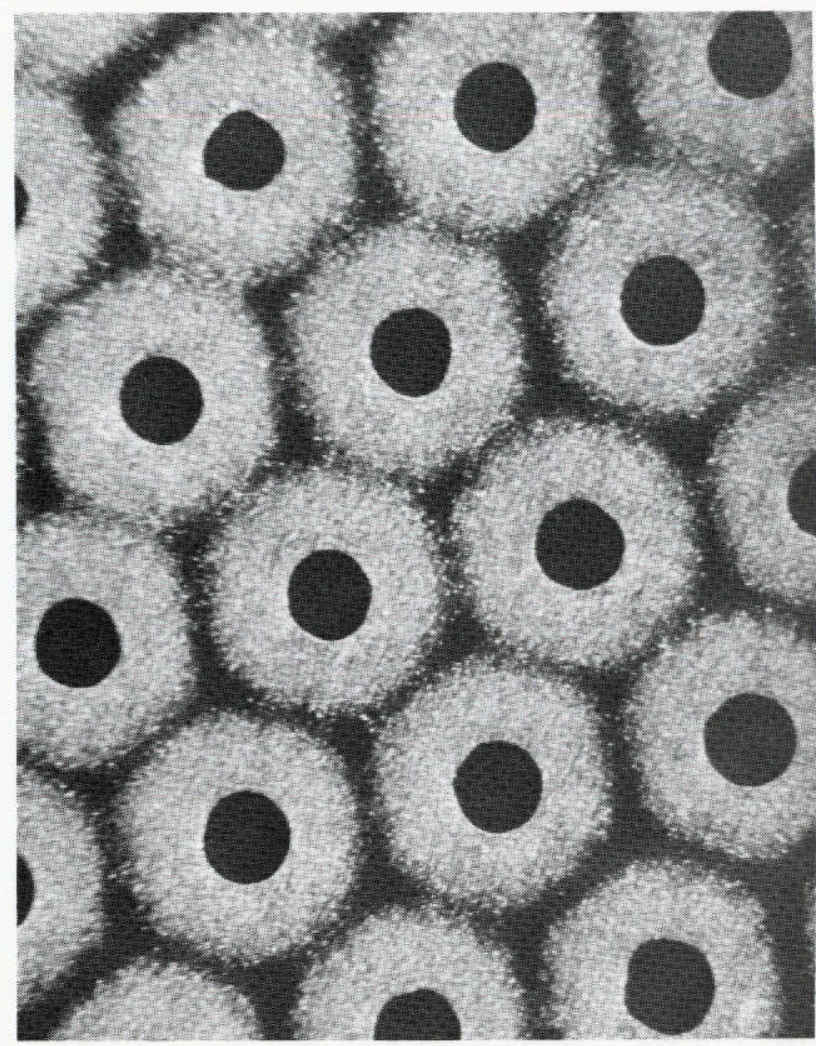

(b)

Figure 10. - Photomicrographs of charge exchange ion sputtering erosion patterns viewed from downstream side of accelerator grid after 462 hours of operation. 


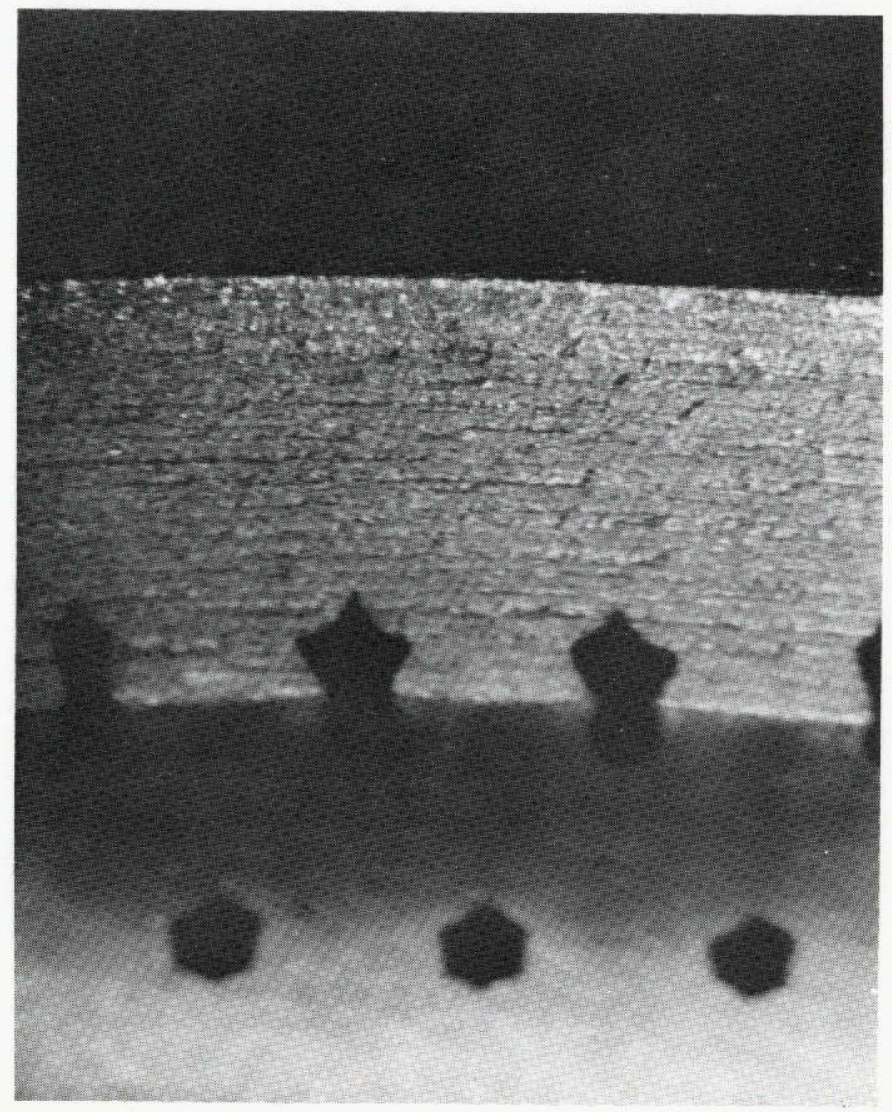

Figure 11. - Photomicrograph of sputtered grooves in accelerator grid mounting ring after 462 hours of operation. 


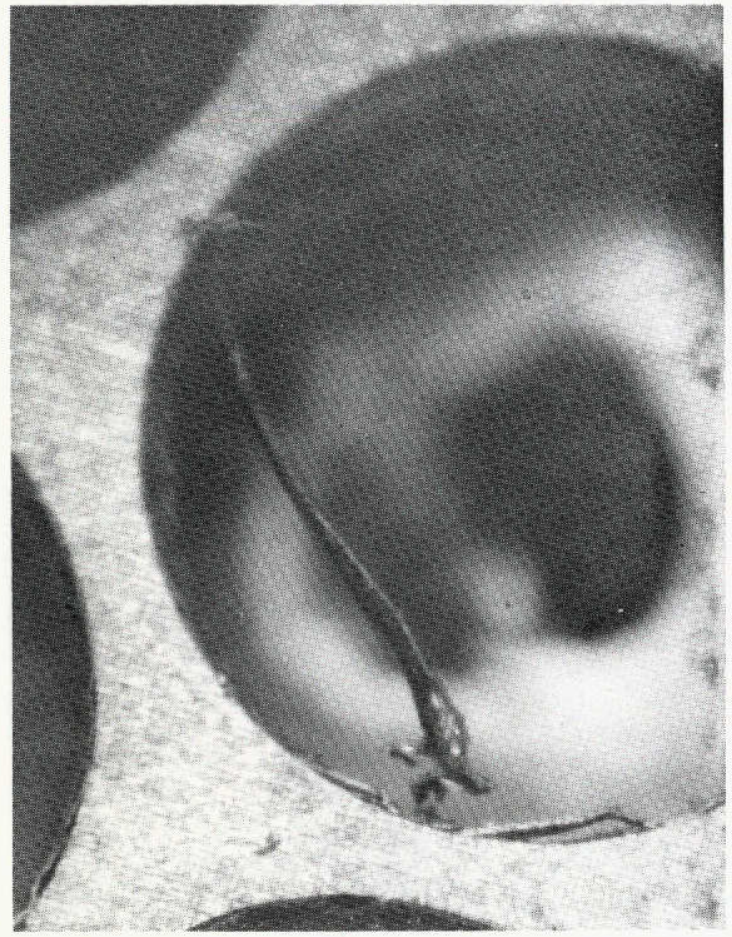

(a)

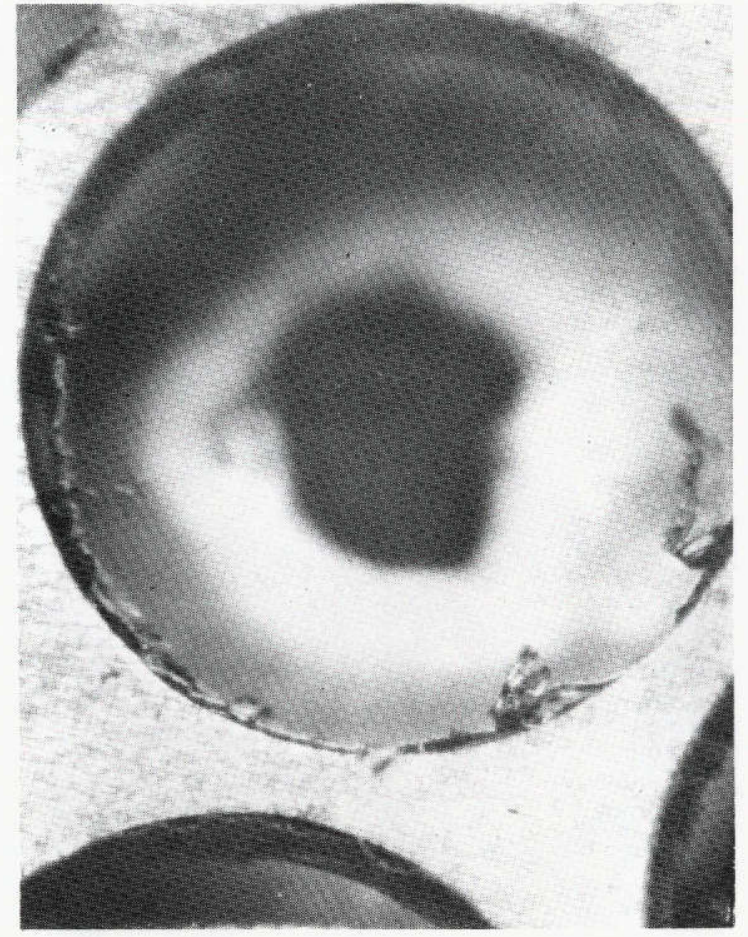

(b)

Figure 12. - Photomicrographs of deposition of sputtered accelerator grid material in screen holes after 20 hours of operation. 


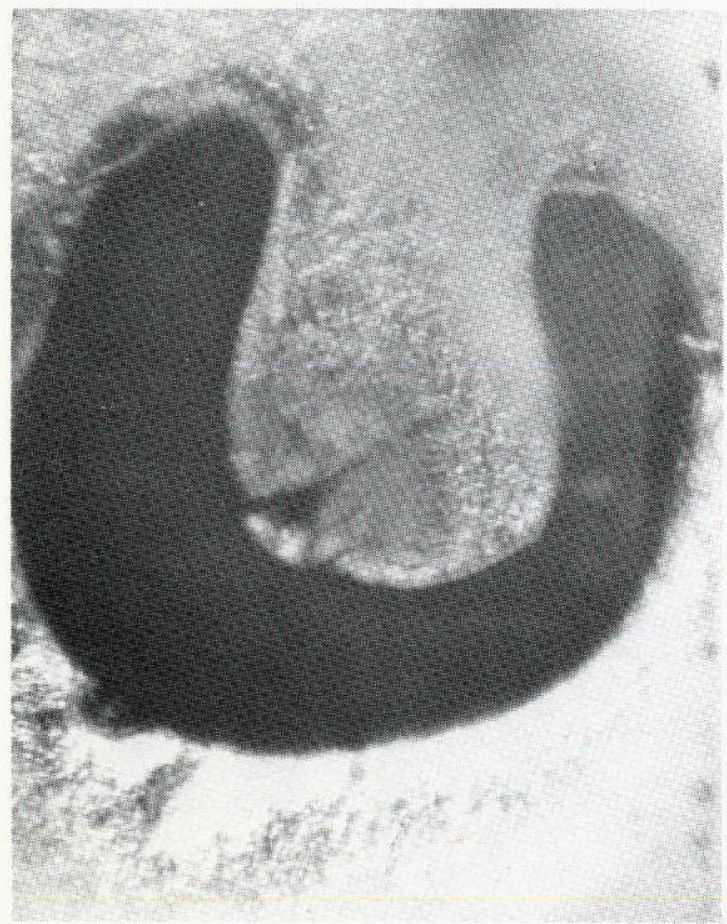

(a)

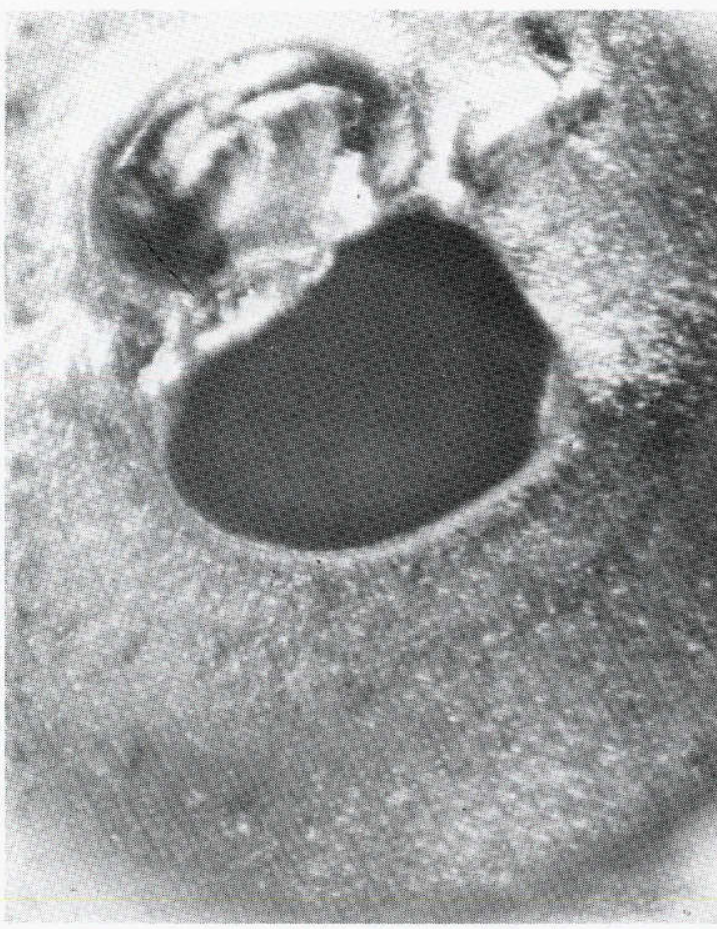

(b)

Figure 13. - Photomicrographs of distorted accelerator grid holes due to peeled flake on screen grid hole walls after 20 hours of operation.

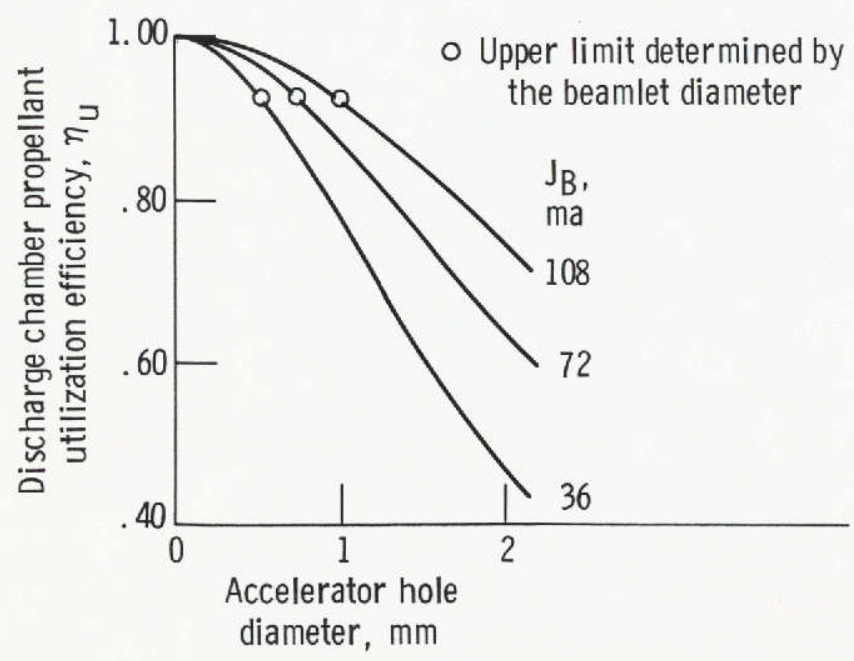

Figure 14. - Propellant utilization efficiency as a function of accelerator hole diameter as predicted by equation $3, \eta_{\mathrm{u}}=1 /\left(1+C D^{2}\right)$ at three beam current levels. 


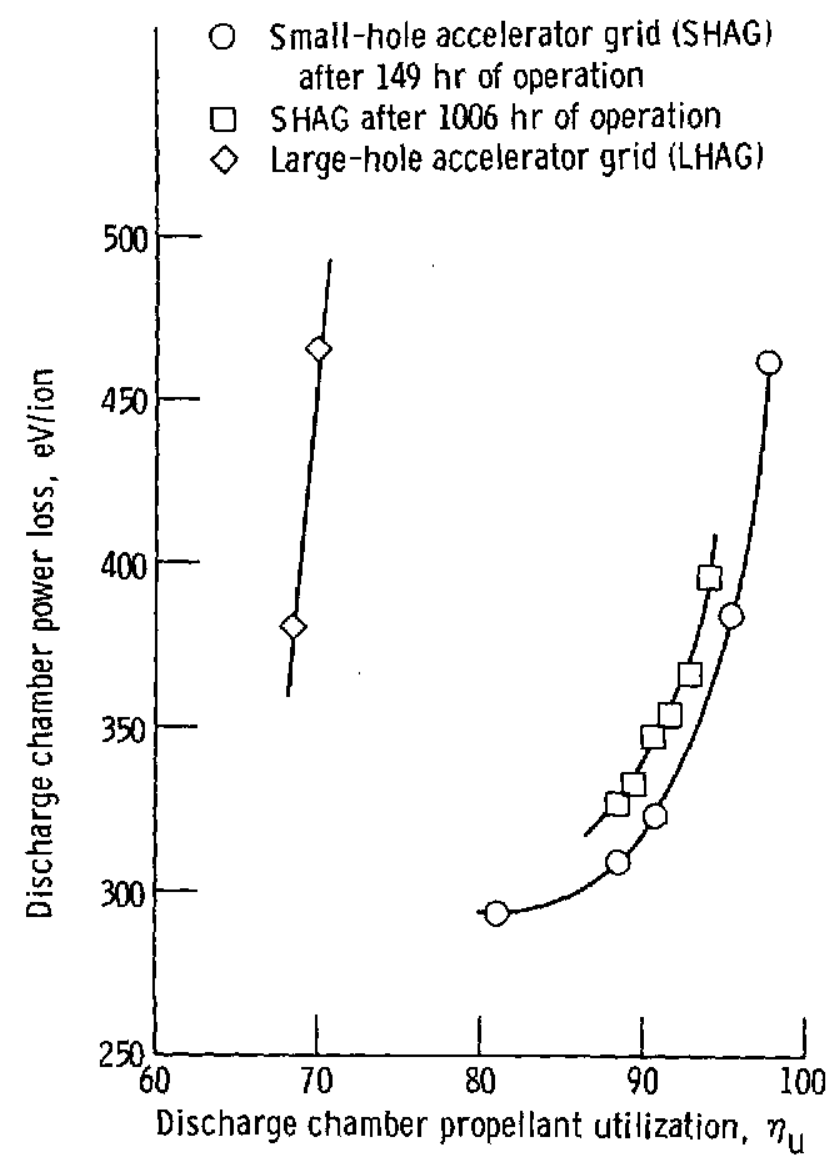

Figure 15. - Discharge chamber power loss as function of discharge chamber propellant utilization for thruster with ion-machined accelerator grid. Net accelerating voltage, $V_{I}, 1220$ volts; accelerator voltage, $V_{A}$, -300 volts. (Data taken at constant mercury flow. )
$\mathrm{J}_{\mathrm{B}}$, Thrust, $\Delta V_{\mathrm{I}}$, ma $\mathrm{mN} V$

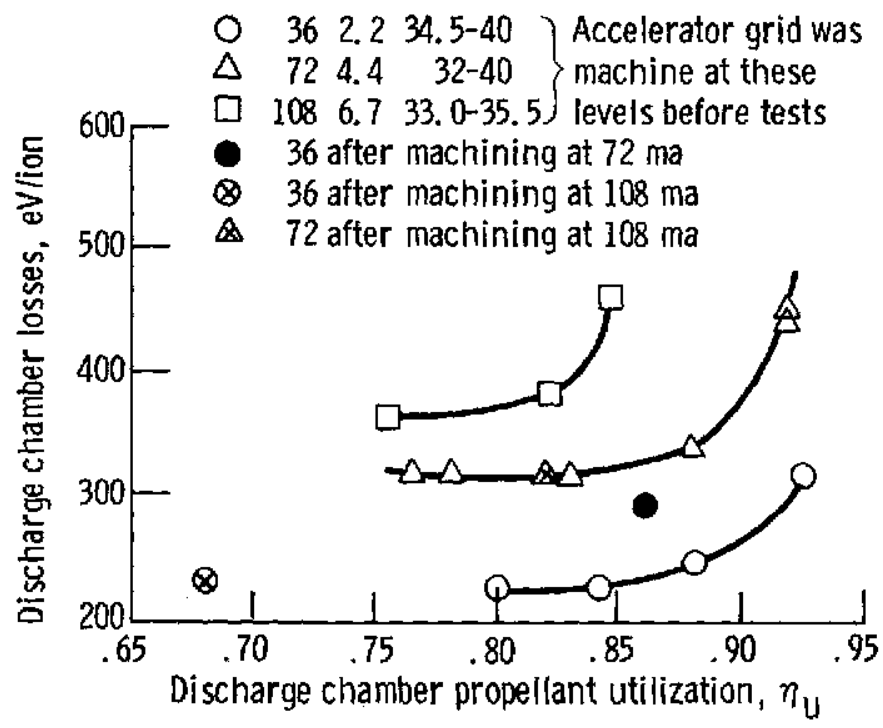

Figure 16. - Discharge chamber losses are plotted as a function of discharge chamber propellant utilization at three beam current levels. $V_{I}=$ $1220 \mathrm{~V}, \mathrm{~V}_{\mathrm{A}}=-300 \mathrm{~V}$ 


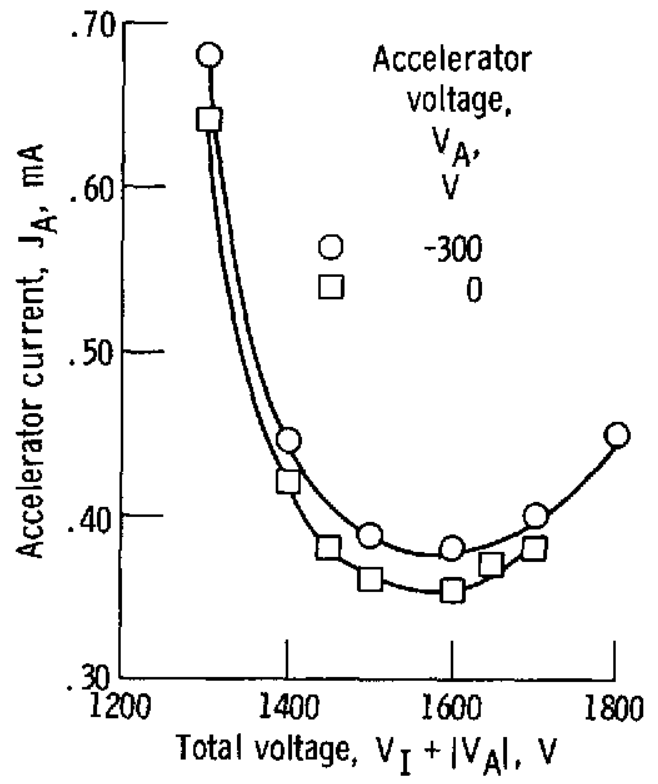

Figure 17. Accelerator current dependence on total voltage. Beam current, $\mathrm{J}_{\mathrm{B}}, 72 \mathrm{~mA}$; propellant utilization efficiency, $\eta_{U}, 88.5$ percent. (Data taken after $149 \mathrm{hr}$ of operation. ) 